\title{
Study of IR spectra of thiacalix[4]arene with carboxyl and adamantyl groups
}

\author{
Victor Furer ${ }^{1 *[0000-0002-3637-5731]}$, Ludmila Potapova ${ }^{1[0000-0002-5403-1836]}$, Ivan Vatsouro $^{2}$, \\ Vladimir Kovalev [0000-0003-4473-1107], and Elvira Shokova ${ }^{2}$ \\ ${ }^{1}$ Kazan State University of Architecture and Engineering, 420043, Zelenaya st., Kazan, Russia \\ ${ }^{2}$ Moscow state university, 119991, Lenin's Hills, Moscow, Russia
}

\begin{abstract}
The IR spectra of $p$-(3-carboxy-1-adamantyl)thiacalix[4]arene (1) were studied. IR spectra of compound 1 do not contain bands of free hydroxyl groups. The $\mathrm{vOH}$ value at $3377 \mathrm{~cm}^{-1}$ signifies the formation of an intramolecular H-bond along the lower edge of compound 1. It was found that all the studied calixarene derivatives containing adamantylcarboxylic acid fragments on the upper edge form $\mathrm{H}$-bonds between adjacent carboxyl groups. At the top edge of thiacalixarene, carboxyl groups form dimers or cyclic tetramers through intramolecular H-bonds. The conformation of the cone is preserved, but there is a mutual influence of $\mathrm{H}$ bonds along the lower and upper edges of the thiacalixarene molecules. A structure with dimeric H-bonds between carboxyl groups is $1.5 \mathrm{~kJ} / \mathrm{mol}$ less preferable than the conformation with tetrameric cyclic H-bonds of compound 1. Comparison of the $\mathrm{vOH}$ absorption frequency of alcohol hydroxyl groups in IR spectra of thiacalixarenes shows that the presence of the second H-bond system weakens the H-bonds of alcohol hydroxyl groups slightly.
\end{abstract}

Keywords: calixarenes, IR spectroscopy, Hydrogen bonding, Normal modes, DFT.

\section{Introduction}

Calixarenes are excellent building materials for the design of new guest molecules for supramolecular chemistry [1-5]. In thiacalixarenes, the introduction of sulfur atoms as a bridge opens up additional opportunities for changing the ring size, conformation, and binding properties of macrocycles [5-7]. Adamantyl thiacalixarenes are readily soluble in organic solvents [2]. In addition, they have several positions for the attachment of substituents, which help to regulate the ability of molecules to form complexes. It has been shown that carboxylated calixarenes are receptors for amines, metal ions, and aromatic hydrocarbons [8].

Earlier, we showed that thiacalix[4]arenes with large adamantyl substituents are in the cone conformation $[9,10]$. It is known that carboxylic acids form dimers via H-bonds [11].

\footnotetext{
* Corresponding author: furer@kgasu.ru
} 
IR spectroscopy is a traditional method for studying $\mathrm{H}$-bonds in supramolecular systems [12-16].

In this work, the H-bonds and the conformation of the previously synthesized p-(3carboxy-1-adamantyl)thiacalix[4]arene (1) were investigated using IR spectroscopy and density functional theory (DFT). It is important to know how additional H-bonds along the upper rim of thiacalixarene affect the molecular structure. We calculated the structure and IR spectra of compound $\mathbf{1}$ for dimeric and tetrameric complexes formed by carboxyl groups. These studies are important for the synthesis of therapeutic drugs and tubes, and the development of new stabilizers, for macromolecules.

\section{Materials and methods}

The synthesis of p-(3-carboxy-1-adamantyl)thiacalix[4]arene (1) is presented in [8] (Fig. 1). This compound was obtained from p-H-thiacalix[4]arene and 3-carboxy-1-adamantol. For comparison, we also studied p-(3-carboxy-1-adamantyl) calix[4]arene (2) and adamantylthiacalix[4]arene (3) (Fig. 1).

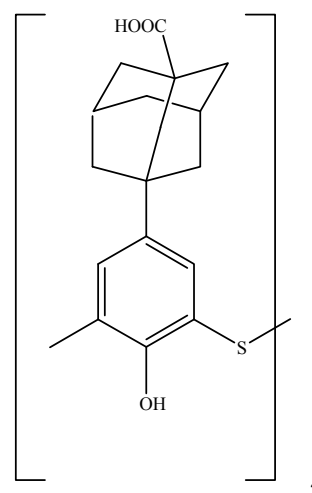

1
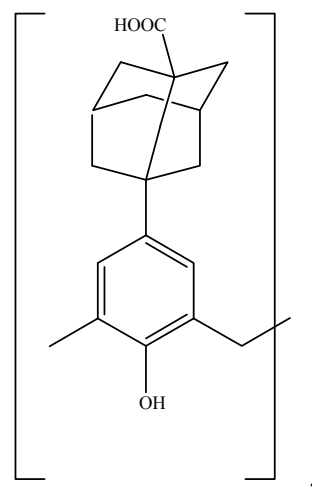

2

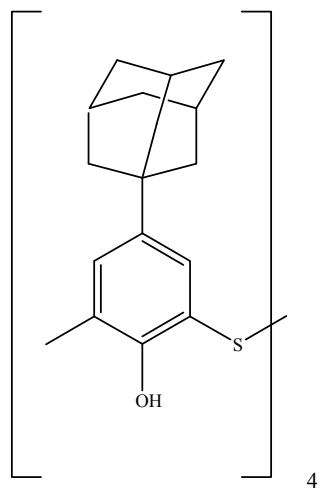

3

Fig. 1. Structure of compounds 1 (1), 2 (2) and 3 (3).

The melting and decomposition points of these compounds are rather high $\left(350^{\circ} \mathrm{C}\right.$ and higher) [1]. Sample compounds were gradually heated to $250^{\circ} \mathrm{C}$.

IR spectra were recorded with a Bruker IR spectrophotometer. Quantum-chemical calculations of the molecule (1) were carried out by the density functional method using the Gaussian09 program.

\section{Results}

In IR spectra of compound $\mathbf{1}$ in different states of aggregation, there are no frequencies of free stretching vibrations of hydroxyl groups (Fig. 2, Table). Hence, we can conclude that all hydroxyl groups are involved in intramolecular H-bonds. Besides, alcohol $\mathrm{OH}$ groups form H-bonds with a frequency $\mathrm{vOH}$ of $3377 \mathrm{~cm}^{-1}$ (Fig. 2).

Table. Measured frequencies $v \mathrm{OH}$.

\begin{tabular}{|c|c|c|c|c|}
\hline Compound & Original sample, $\mathrm{T}_{\mathrm{K}}$ & $\mathrm{T}=250^{\circ} \mathrm{C}$ & Cooled sample, $\mathrm{T}_{\mathrm{K}}$ & Solution in $\mathrm{CCl}_{4}$ \\
\hline $\mathbf{1}$ & 3377 & 3372 & 3391 & 3379 \\
\hline $\mathbf{2}$ & 3226,3418 & 3251,3534 & 3228 & 3152 \\
\hline $\mathbf{3}$ & 3372 & 3375 & 3372 & 3254 \\
\hline
\end{tabular}


Comparison of $v \mathrm{OH}$ of compound 1 at $3377 \mathrm{~cm}^{-1}$ with the corresponding band at $3372 \mathrm{~cm}^{-1}$ in compound 2 shows that the presence of the second system of H-bonds of carboxyl groups in the first compound only slightly weakens the H-bonds of alcohol hydroxyl groups (Fig. 2).

Under the action of H-bonds on the upper rim of thiacalixarene molecules, the cooperation of H-bonds of hydroxyl groups is weakened, and the $\mathrm{vOH}$ frequency increases. Of course, the cone conformation in these molecules is retained.

A doublet of bands at 1777 and $1697 \mathrm{~cm}^{-1}$ is observed in the IR spectrum of compound 1 in the crystalline state (Fig. 2).

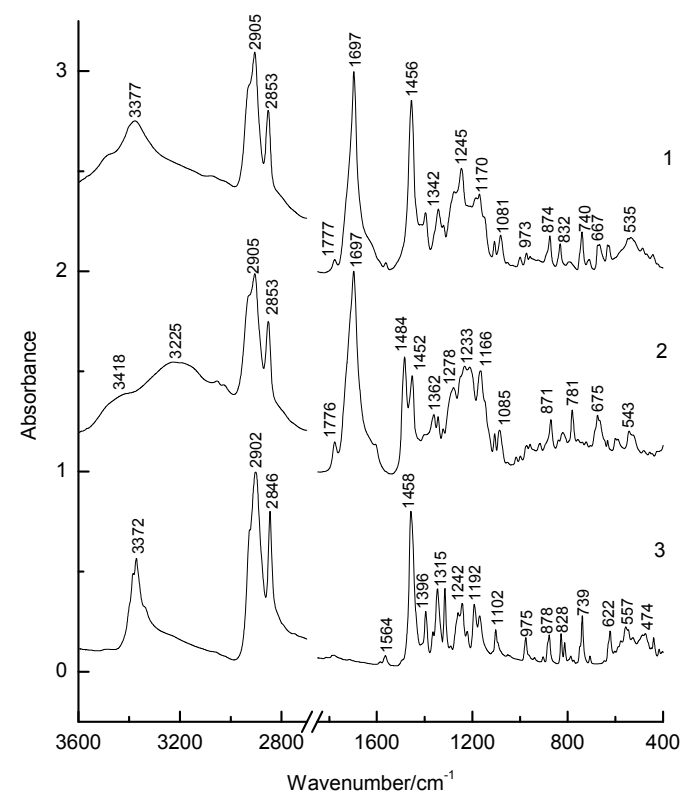

Fig. 2. Measured IR spectra of compounds 1 (1), 2 (2), and 3 (3).

The first band can be attributed to vibrations of free carboxyl groups, and the second frequency to vibrations of $v(\mathrm{C}=\mathrm{O})$ groups involved in the formation of H-bonds. Analysis of the intensity of the bands shows that most of the carboxyl groups are involved in the formation of H-bonds. The thiacalixarene macrocycle spatially restricts the formation of $\mathrm{H}$ bonds and leads to a noticeable asymmetry of carboxyl group dimers. Unfortunately, the limited solubility of thiacalixarene 1 prevents the observation of free vibration bands of vOH between 3700 and $3500 \mathrm{~cm}^{-1}$.

The molecules of thiacalixarenes differ from classical calixarenes by the large size of the macrocycle and the electronic effect of sulfur atoms; therefore, the H-bond in thiacalixarenes is weaker. In the IR spectrum of molecule $\mathbf{1}$ in the $\mathrm{vOH}$ region there is a band at $3372 \mathrm{~cm}^{-1}$ with a shoulder at $3395 \mathrm{~cm}^{-1}$.

The IR spectrum of the corresponding classical calixarene 2 contains bands at 3226 and $3418 \mathrm{~cm}^{-1}$. Thus, the weakening of the cyclic H-bond in thiacalixarenes in comparison with classical calixarenes manifests itself in an increase in the $\mathrm{vOH}$ frequency. 


\section{Discussion}

DFT calculations of molecule 1 were carried out, taking into account the possibility of the formation of dimers of carboxyl groups and H-linked rings (Fig. 3). Both variants of the formation of H-bonds of carboxyl groups were considered - H-linked dimers and cyclic chains. It turned out that the scheme with two H-linked dimers from carboxyl groups in molecule $\mathbf{1}$ is $1.5 \mathrm{~kJ} / \mathrm{mol}$ less favorable. It is interesting to note that in classical calixarene $\mathbf{2}$, the formation of dimeric complexes of carboxyl groups is more favorable. The larger size of the calixarene macrocycle reduces steric hindrances to the formation of a cyclic system of H-bonds on the upper rim.

Besides, due to the effect of steric stress, the carboxyl groups in the dimers become nonequivalent. Since the energy difference is small, the existence of two types of complexes formed by H-bonds is quite probable.

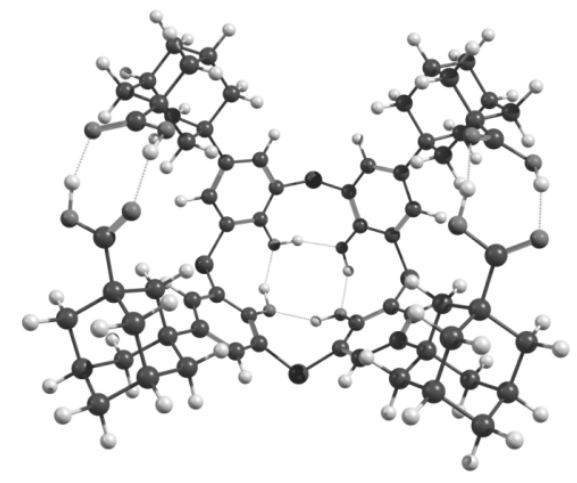

1

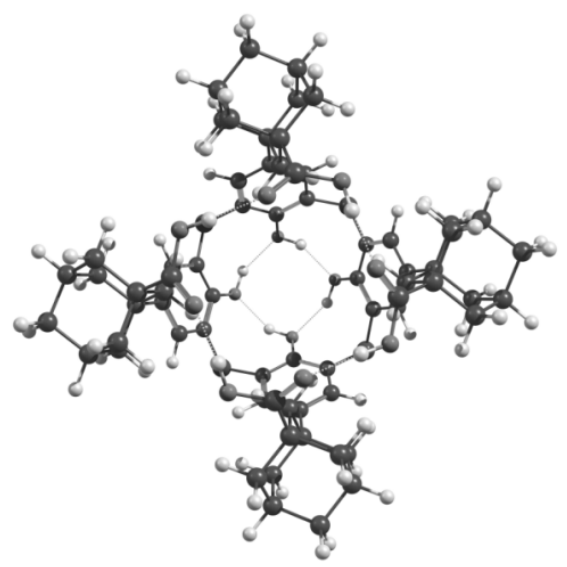

2

Fig. 3. The structure of molecule $\mathbf{1}$ in the cone conformation with a cyclic system of H-bonds along the lower rim and dimers (1) and cyclic H-bonds along the lower rim (2).

So, the distance between oxygen atoms is $2.65 \AA$ for the external H-bond, while for the internal H-bond of the dimer, it is $2.68 \AA$. Therefore, the spectrum of compound 1 contains two bands $v(\mathrm{C}=\mathrm{O})$. It is important to emphasize that these parameters of the H-bonds of dimers of carboxyl groups do not change on going to the classical calixarene 2 . Dimers have a closed localized structure that changes little on going from molecule $\mathbf{1}$ to molecule 
2. As follows from Fig. 2, the frequencies of the carboxyl groups in the IR spectra of compounds 1 and $\mathbf{2}$ remain unchanged.

For a cycle of four carboxyl groups of molecule 1, oxygen atoms are spaced $2.68 \AA$ on the upper rim and $2.85 \AA$ on the lower rim (Fig. 3). The corresponding parameters for classical calixarene 2 are $2.67 \AA$ and $2.69 \AA$ Á. For this type of complex, the parameters of the H-bonds of carboxyl groups change very little, while the sizes of macrocycles in molecules $\mathbf{1}$ and $\mathbf{2}$ differ markedly.

The strength of hydrogen bonding can be described using the Wiberg bond indices [17]. For molecule 1, the average order of the H-bonds of the cycle on the lower ring is 0.057 , which is noticeably less than the corresponding parameter of 0.097 in molecule 2 . These values of the Wiberg indices are consistent with the fact that thiacalixarenes have weaker H-bonds at the lower rim of the molecules as compared to classical calixarenes.

For H-bonds of dimeric associates of $\mathrm{COOH}$ groups of molecule 1, the Wiberg indices are 0.093 and 0.087 . These values show that the external H-bonds of dimeric complexes are stronger than the internal ones, and the corresponding parameters of molecules $\mathbf{1}$ and $\mathbf{2}$ change insignificantly. The order of H-bonds for cyclic associates at the upper and lower edges of molecule 1 is 0.079 and 0.043 , respectively. It turned out that the H-bonds on the upper and lower rims of the molecule affect each other, and in thiacalixarenes, the H-bonds are weakened.

The torsion angles $\varphi(\mathrm{C} 17-\mathrm{C} 18-\mathrm{S} 2-\mathrm{C} 35)$ and $\chi(\mathrm{C} 18-\mathrm{S} 2-\mathrm{C} 35-\mathrm{C} 36)$ determine the conformation of calixarenes [18]. The dihedral angles of molecule $\mathbf{1}$ for dimeric associates of carboxyl groups are 95.0 and $94.9^{\circ}$, and for cyclic tetrameric H-bonds, they are 89.3 and $89.4^{\circ}$. In molecule 2 , these angles are 97.2 and $97.4^{\circ}$, respectively. We see that $\mathrm{COOH}$ complexes of calixarene groups affect the orientation of aromatic fragments. The rest of the geometric parameters of the molecules remain unchanged.

We calculated the IR spectra of compound 1 with dimeric and tetrameric associates on the upper rim (Fig. 4). An intense band at $1697 \mathrm{~cm}^{-1}$ and a weak band at $1777 \mathrm{~cm}^{-1}$ are caused by $v \mathrm{C}=\mathrm{O}$ of $\mathrm{COOH}$ groups in IR spectrum 1 . Bending vibrations of methylene groups of adamantyl substituents give rise to a band at $1456 \mathrm{~cm}^{-1}$. The IR spectrum shows bands at $1417,1396,1342,1321 \mathrm{~cm}^{-1}$, caused by bending $\mathrm{CH}$ vibrations and wagging vibrations of methylene groups (Fig. 4). Stretching vibrations of $\mathrm{CC}$ and $\mathrm{CO}$ bonds and bending vibrations of $\mathrm{CH}$ bonds appear in the range of $1280-1200 \mathrm{~cm}^{-1}$ of IR spectrum 1 . Frequencies in the range of $1190-1100 \mathrm{~cm}^{-1}$ of the IR spectrum of compound 1 were assigned to the torsion of methylene groups and deformation of $\mathrm{CH}$ bonds. Stretching vibrations of CC bonds and bending of methylene groups give bands at 1081, 1053, 1033 $\mathrm{cm}^{-1}$ in the IR spectrum of compound 1 . The bands at $999,973,958$, and $924 \mathrm{~cm}^{-1}$ in the IR spectrum of 1 were assigned to stretching vibrations of $\mathrm{CC}$ bonds, wagging vibrations of methylene groups, and bending vibrations of CCC angles.

Stretching vibrations of CC bonds and rocking vibrations of methylene groups cause the appearance of bands at $891,874,832 \mathrm{~cm}^{-1}$ in the IR spectrum of compound 1 . Stretching vibrations of CC bonds determine the frequencies $795,740,710 \mathrm{~cm}^{-1}$ in IR spectra 1 . The bands at $674,667,633,626 \mathrm{~cm}^{-1}$ in the IR spectrum of 1 were identified as bending vibrations of the angles of the skeleton of the molecule. The bands at 547, 535, 486, 469, $443,425 \mathrm{~cm}^{-1}$ in the IR spectrum of 1 are due to skeletal vibrations of the macrocycle.

It is important to reveal the characteristic features of the IR spectra of thiacalix[4]arene 1 for dimeric and tetrameric associates of carboxyl groups on the upper rim of the molecules (Fig. 4). For analytical purposes, molecular bands of 1 1454, 1264, 1238, 724 $\mathrm{cm}^{-1}$ (dimer), 1223, 1192, $652 \mathrm{~cm}^{-1}$ (tetramer) were isolated. 


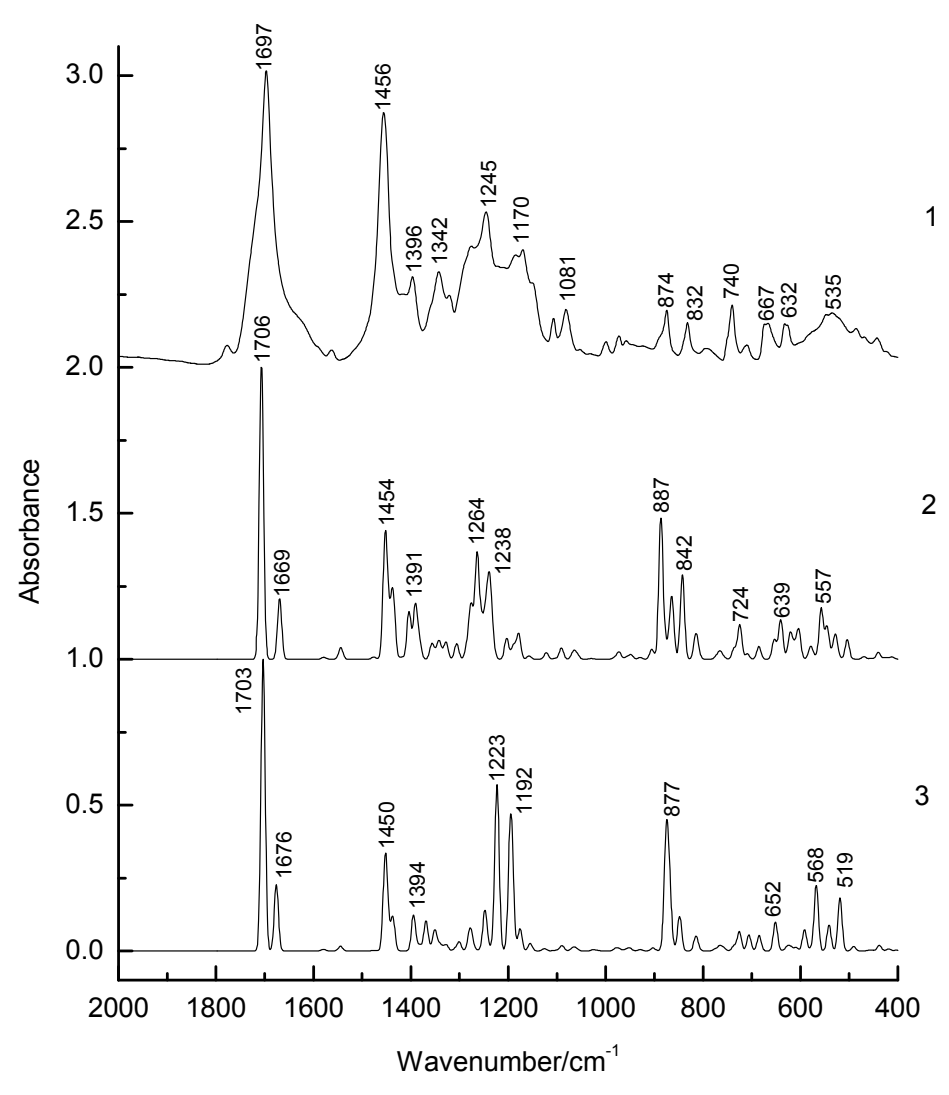

Fig. 4. Measured (1) and calculated IR spectra of molecule 1 in the cone conformation with a cyclic system of H-bonds along the lower rim and dimers (2) and cyclic H-bonds along the lower rim (3).

\section{Conclusion}

The IR spectra of compounds $\mathbf{1}, \mathbf{2}$, and $\mathbf{3}$ were studied in the crystalline state, in solution, and at various temperatures. Intramolecular hydrogen bonds are formed between $\mathrm{COOH}$ groups and are realized in the form of dimers or tetramers. Complexes of hydrogen bonds of $\mathrm{COOH}$ and $\mathrm{OH}$ groups influence each other.

In thiacalix[4]arene 1, this causes a slight weakening of the cooperative cyclic intramolecular H-bond in comparison with molecule 2 . These compounds are used in manufacturing processes to extend the life of resins and other polymeric materials.

\section{References}

1. P. Neri, J. Sessler, M.X. Wang, (Eds.). Calixarenes and beyond, Springer International Publishing, Switzerland (2016) DOI: 10.1007/978-3-319-31867-7 
2. X. Fan, X. Guo, J. Mol. Liquids, 325, 115246 (2021) DOI: 10.1016/j.molliq.2020.115246

3. L. Gallego-Yerga, C. de la Torre, F. Sansone, A. Casnati, C.O. Mellet, J.M.G. Fernandez, V. Cena, Carbhydrate Polym., 252, 117135 (2021) DOI: 10.1016/j.carbpol.2020.117135

4. M. N. Gabdulkhaev, M. A. Ziganshin, A. V. Buzyurov, C. Schick, S. E. Solovieva, E. V. Popova, A. T. Gubaidullin, V. G. Gorbatchuk, Cryst. Eng. Comm., 22, 7002 (2020) DOI: 10.1039/D0CE01070G

5. D. N. Shurpik, P. L. Padya, I. I. Stoikov, P. J. Cragg, Molecules, 25, 5145 (2020) DOI: 10.3390/molecules25215145

6. R. Zadmard, F. Hokmabadi, M. R. Jalali, A. Akbarzadeh, RSC Adv., 10, 32690 (2020) DOI: 10.1039/D0RA05707J

7. L. Baldini, A. Casnati, F. Sanasone, Eur. J. Org. Chem., 2020, 5056 (2020) DOI: 10.1002/ejoc. 202000255

8. E. A. Shokova, V. A. Tafeenko, V. V. Kovalev, Tetrahedron. Lett., 43, 5153 (2002) DOI: $10.1016 / \mathrm{S} 0040-4039(02) 00977-2$

9. V. L. Furer, L. I. Potapova, V. I. Kovalenko, J. Mol. Struct., 1128, 439 (2017) DOI: 10.1016/j.molstruc.2016.09.010

10. V. L. Furer, L. I. Potapova, I. M. Vatsouro, V. V. Kovalev, E. A. Shokova, V. I. Kovalenko, J. Mol. Struct., 1171, 207 (2018) DOI: 10.1016/j.molstruc.2018.06.008

11. L. Bellamy, The Infra-red Spectra of Complex molecules. Springer Netherlands, (1980)

12. V. L. Furer, A. E. Vandyukov, S. R. Zaripov, S. E. Solovieva, I. S. Antipin, V. I. Kovalenko, Vibr. Spectr., 95, 38 (2018) DOI: 10.1016/j.vibspec.2018.03.003

13. V. L. Furer, L. I. Potapova, D. V. Chachkov, I. M. Vatsouro, V. V. Kovalev, E. A. Shokova, V. I. Kovalenko, J. Mol. Model., 26, 179 (2020) DOI: 10.1007/s00894-02004441-1

14. V. L. Furer, L. I. Potapova, V. I. Kovalenko, Izvestiya KGASU. 55, 39 (2021) DOI: $10.52409 / 20731523 \_2021 \_1 \_39$

15. V. L. Furer, V. I. Kovalenko, Izvestiya KGASU, 51, 154 (2020)

16. L. I. Potapova, V. L. Furer, V. I. Kovalenko, Izvestiya KGASU, 51, 138 (2020)

17. K. A. Wiberg, Tetrahedron, 24, 1083 (1968) DOI: 10.1016/0040-4020(68)88057-3

18. F. Ugozzoli, G. D. Andretti, J. Incl. Phenom., 13, 337 (1992) DOI: 10.1007/BF01133233 